\title{
Turbulência e Suspensão': Sobre estados e atravessamentos
}

\author{
Marina Martins \\ Universidade Federal do Rio de Janeiro - UFRJ, Rio de Janeiro/RJ, Brasil \\ E-mail: corpoprismatico@gmail.com
}

\section{Resumo}

O texto reflete sobre a linguagem poética da dança e o processo de criação do filme Enquanto caem as folhas...(2015) focando na categoria Esforço do Sistema Laban/Bartenieff de Análise do Movimento e observando como as combinações dos fatores de qualidade do movimento e suas variações dinâmicas afetaram o roteiro, a edição e a preparação corporal das personagens. O filme investiga como os padrões de desenvolvimento do movimento e os perfis psicológicos estudados pela Dra. Judith Kestenberg (1910-1999) estão conectados à Teoria dos Esforços de Rudolf Laban (1879-1958) e aos Princípios Fundamentais do Movimento de Irmgard Bartenieff (1900 -1981). Inspirado na obra da escritora e cineasta de língua francesa, Marguerite Duras (1914-1996), o filme destaca personagens que têm em comum traços de loucura, abandono, tédio e dor.
The text reflects on the poetic language of dance and the process of creating the film While the leaves fall... (2015) focusing the Effort on the Laban/Bartenieff Movement Analysis System and observing how the combinations of movement quality factors and their dynamic variations affected the script, editing and body preparation of the characters. The film investigates how movement patterns and psychological profiles, studied by Dr. Judith Kestenberg (19101999), are connected to Rudolf Laban's Theory of Efforts (1879-1958) and the Fundamentals Principles of Movement by Irmgard Bartenieff (1900-1981). Inspired by the work of french-speaking writer and filmmaker Marguerite Duras (1914-1996), the film highlights characters who have in common traces of madness, abandonment, boredom and pain. 


\section{Trajetórias transversas:} Sobre Marguerite Duras²

\section{Figura 1 - Making off. Leitoras: Bruna Fiúza e Flávia Cruz.}

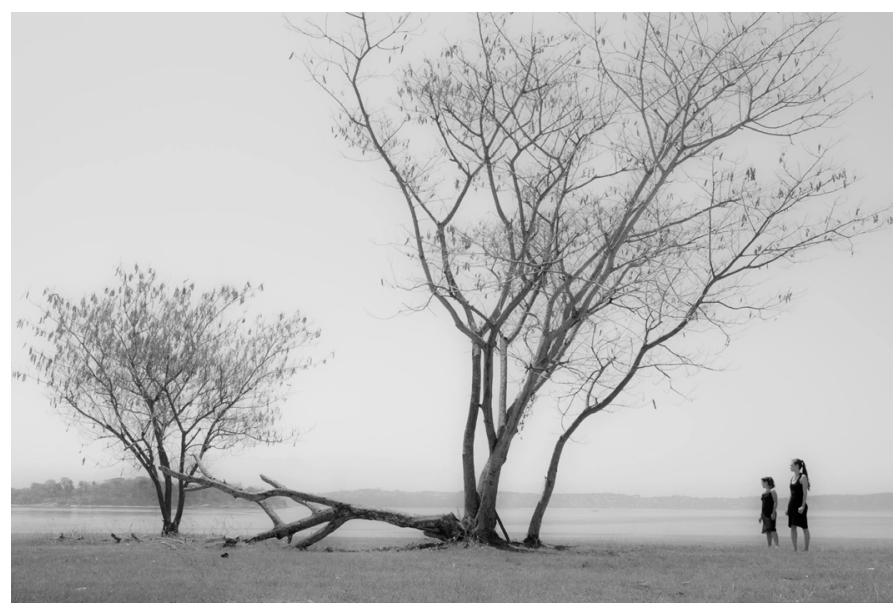

Fonte: Foto de Marina Pachecco. Ilha do Fundão, RJ. 2012.

1 Livre tradução do termo "stillness and stir" do poema Stillness and Stir: a short extract from poetic musings, de Rudolf Laban (1984), publicado no livro A Vision of Dynamic Space: London and Philadelphia: The Falmer Press, 1984.

2 Além da literatura Marguerite Duras também se dedicou ao cinema, atuando como roteirista e diretora. De início, fazendo parte da nouvelle vague francesa, movimento este amplamente dominado pelos homens, escreveu o roteiro do filme Hiroshima Meu Amor, dirigido por Alan Resnais, em 1959, para depois realizar seus próprios filmes em meados dos anos 1960. A cineasta transforma em imagem cinematográfica o estado silencioso e indefinido de suas personagens por meio de uma linguagem desconhecida e estranha. O Amante (1984), foi o romance que ganhou o prêmio Goncourt de literatura francesa, nele a autora revela a história da adolescente, residente no liceu francês, que mantinha um caso amoroso com um belo e rico homem chinês.
O filme Enquanto caem as folhas... ${ }^{3}$ integra as linguagens poéticas da literatura, da dança e do cinema, explorando a cinestesia (sensação espacial do movimento) como lugar de interseção e transversalidade entre elas. Livremente inspirado na obra de Marguerite Duras (Saigon, 1914 - Paris, 1996), parte do conceito de plano no cinema, cujo enquadramento nos "aproxima da pele das coisas"4 para destacar a potência do corpo feminino em movimento como discurso que fala por si. No filme não há diálogos nem narrativa em off, somente música e movimento.

A câmera-olho ${ }^{5}$, aquela que capta o mistério, o desejo e a morte, também foi colocada no espaço cênico como uma câmera-bailarina, fazendo o papel de narradora. Ela se desloca pelo espaço impulsionada pela dinâmica musical e captura as sequências coreográficas, ora isolando ora sobrepondo personagens, revelando, como no cinema impressionista, sentimentos e estados

30 projeto Corpo Prismático: Artes Integradas na Dança, produção do filme Enquanto caem as folhas... foi realizado pelo Laboratório de Pesquisa e Criação Cênica (LAPECC/DAC/UFRJ) que recebeu apoio institucional da Fundação Carlos Chagas Filho de Amparo a Pesquisa do Estado do Rio de Janeiro (FAPERJ) e da Pró-Reitoria de Extensão (Pr5) da Universidade Federal do Rio de Janeiro (UFRJ) - 2011-2013. O filme foi concluído 2 anos depois, em 2015. Dando continuidade à pesquisa literária relacionada à dança, em 1993 reuni a obra da escritora francesa Marguerite Duras, estudada em um dos últimos cursos da graduação na UNI-RIO para realizar, como diretora assistente, coreógrafa e bailarina, a Trilogia Marguerite Duras em parceria com a Cia. Atores Bailarinos do Rio de Janeiro. Assim, fez-se uma releitura da obra durassiana pelo viés coreográfico, montando a partir da peça Savannah Bay a coreografia chamada de Exílio; do romance Moderato Cantabile, filmado por Peter Brook, uma coreografia homônima que misturava os dois casais da história: o que praticou o crime e o que comenta sobre ele. E, por fim, S.Thala, uma reunião da obra da autora apresentada como instalação-cênica-multimídia no espaço vertical da Fundição Progresso no Rio de Janeiro.

4 Citação do Prof. Sérgio Almeida da Escola de Cinema Darcy Ribeiro, em mesa redonda na Casa de Rui Barbosa/RJ após exibição do filme, em abril de 2016.

5 O conceito de câmera-olho: "Eu sou o cine-olho. Eu sou o olho mecânico. Eu, máquina, mostro-lhe o mundo como somente eu sou capaz de ver», Dziga Vertov (1924). 
de alma. A montagem procurou nos meios cinematográficos desenvolver uma dramaturgia da imagem (cor, ritmo, dinâmica e efeitos especiais) sobre uma estrutura cíclica, de evolução espiralada que avança em fluxo contínuo. Nunca termina, nem se completa, que segue deslizante ao modo do cinema de M. Duras no qual o clímax sempre é interrompido.

O projeto reuniu estudantes dos cursos de dança da UFRJ e profissionais do cinema para produzir esta obra de ficção em dança, no intuito de apreender o significado desse estado de dor e melancolia dos discursos artísticos femininos, especialmente esses que permeiam a literatura e o cinema de Marguerite Duras.

Filha de humildes professores franceses enviados à colônia no início do século XX, Marguerite Donnadieu nasceu em 1914, em Gia-Dinh perto de Saigon, Indochina, hoje Vietnam. Ao mesmo tempo glamoroso e decadente, seu universo literário e cinematográfico foi construído do ponto de vista do exílio como uma condição inerente à situação da escritora errante e solitária. De modo geral, sua narrativa discorre de texto em texto sobre um estado incerto, adquirido provavelmente durante sua infância na Indochina em meio as chuvas tropicais, a travessia dos rios, a invasão marítima, a loucura da mãe, a solidão. As marcas dessa juventude aparecem como temas recorrentes em histórias que são contadas por vozes femininas fortes e melancólicas. Essas vozes descrevem um constante movimento de desconstrução, tanto da ideia de espaço geográfico, daquilo que tem dimensão, latitude, longitude e profundidade, quanto da noção literária de sujeito que conduz uma narrativa. As personagens se esforçam para não esquecer, elas falam em livre fluxo de consciência sobre o passado, o lugar de origem, as lembranças do corpo, das marcas, do desejo. Tudo parece flutuar à deriva, sem um porto seguro interno onde ancorar, sem um centro de gravidade para enraizar. Seu tema principal é a solidão do ser humano desterritoriarizado e sem lugar, deslocado do mapa mundo real. É a dor da manifestação expressiva, da necessidade de escrever como ela mesma diz:
Chorar, é preciso que isso também aconteça. Se chorar é inútil, mesmo assim creio que é preciso chorar. Pois o desespero é tangível. Perdura. A lembrança do desespero, isto perdura. Às vezes mata. Há uma loucura de escrever que existe em si mesma, uma furiosa loucura de escrever, mas não é por isso que se cai na loucura. Ao contrário. A escrita é o desconhecido. [...] É o desconhecido de si mesmo, de sua cabeça, de seu corpo. Escrever não é sequer uma reflexão, é um tipo de faculdade que se possui ao lado da personalidade, paralelo a ela, uma outra pessoa que aparece e avança, invisível, dotada de pensamento, cólera, e que por vezes acaba colocando a si mesma em risco de perder a vida. (DURAS, 1994, p.47,48).

Julia Kristeva, em seu texto sobre a escrita de Marguerite Duras, define a melancolia como "amarga embriaguez", lugar onde o escritor em estado amoroso e depressivo, encontra na dor a "região inacessível da beleza integral" (KRISTEVA,1989). A psicanalista afirma que M. Duras encontra na dor a motivação de seu discurso criando figuras femininas inapreensíveis, incompletas, solitárias, fluidas, delirantes, cujas ações parecem fixadas em um momento específico. Essas mulheres caminham em um estado de quase morte, no "silêncio da dor" (KRISTEVA,1989), parecendo mesmo embriagadas e ausentes, cingidas por um trauma profundo, por uma emoção sexual arrebatada, pela violência da perda, engolfadas pelo abandono. Como sonâmbulas apresentam sintomas de alienação e depressão, sufocadas pelo silêncio a que são submetidas pelas circunstâncias e pelo esquecimento de si mesmas. Nas suas histórias têm como ação principal a deambulação desatenta da realidade, fora do mundo, de tal modo imersas em seu espaço interno, penetram constante e meticulosamente no imaginário do leitor prostrando-o na inércia de uma única nota que reverbera ad eternum...

As vozes femininas ressoam desta deriva, sobrepostas, misturadas, indefinidas, desarmônicas. Tanto a imagem literária quanto a cinematográfica, expressam a necessidade de representação desse estado inexplicável e embora aparentemente linear 
na sua dinâmica narrativa, elas se desdobram em inúmeras camadas sonoras, nos atravessando até os confins de nossas sensações e sentimentos. $O$ leitor se confunde nos elos perdidos do passado, é arrebatado por emoções desmesuradas, percebe os buracos de sentimentos estranhos, a ausência de qualquer coisa, a sexualidade condicionada, a dor. A realidade parece ser de tal modo terrível e inapreensível que a autora nos induz a assumir, envolvidos por esta atmosfera, uma posição também flutuante em que lembrar e esquecer se tornam suporte ou tábua de salvação desse estado onírico de afogamento. Duras então parece usar o silêncio como uma estratégia de linguagem para contradizer essa condição imposta pela linguagem oficial:

O silêncio, segundo Duras, seria a principal forma pela qual as mulheres poderiam resistir à opressão da linguagem. Para ela (como para outras feministas francesas) a principal arma para opressão da mulher tem sido a linguagem dominada pelo homem (e a conseqüente cultura dominada pelo homem). Uma vez que as mulheres compreendam tal opressão, elas podem escolher o silêncio como estratégia para resistir a dominação. O silêncio, paradoxalmente, torna-se o meio de penetrar-se na cultura; ele determina uma brecha, uma lacuna através da qual as mudanças têm a possibilidade de acontecer. (KAPLAN, 1995, p.148).

6 Para a crítica de cinema Ann Kaplan, as mulheres sempre se defrontarão com uma contradição real: se permanecerem em silêncio ficarão fora do processo histórico; se começarem a falar e a escrever como fazem os homens, serão incluídas como parte da história, mas subjugadas e alienadas a ela. De acordo com essa lógica, boa parcela da crítica feminista defende o discurso feminino como aquele que deveria romper com a história por meio de uma linguagem que fosse na contramão da linguagem vigente. O silêncio, segundo M. Duras, seria a principal forma pela qual as mulheres poderiam resistir à opressão da linguagem. "Para ela (como para outras feministas francesas) a principal arma para opressão da mulher tem sido a linguagem dominada pelo homem (e a consequente cultura dominada pelo homem). Uma vez que as mulheres compreendam tal opressão, elas podem escolher o silêncio como estratégia para resistir a dominação. O silêncio, paradoxalmente, torna-se o meio de penetrar-se na cultura; ele determina uma brecha, uma lacuna através da qual as mudanças têm a possibilidade de acontecer". (KAPLAN, 1995, p.148).
Em alguns de seus filmes e principalmente na série dos curtas-metragem (Césarée, As mãos Negativas, Aurélia Vancouver e Aurélia Melbourne - 1979) não vemos a figura das personagens, seu rosto nem seu corpo, mas sua voz, muitas vezes desdobrada em uma terceira pessoa que narra a própria história. Em Aurélia Vancouver por exemplo, navegamos sobre um rio urbano passando por baixo de grandes pontes, enquanto vemos as estruturas das pontes por baixo e ouvimos o eco de um passado de guerra, nas batidas da água nas paredes, a voz parece ler cartas de amor escritas para um desconhecido. Sua narrativa soa do interior da imagem, como se a imagem revelasse o fluxo interno da voz. Aurélia imagina o sexo como aquilo que afirma seu nome e por isso se dirige a um marinheiro desconhecido de olhos verdes e cabelos pretos que o pronuncia várias vezes enquanto a penetra. $O$ filme corresponde ao estilo lírico de Emil Staiger ${ }^{7}$ no contraste com o ambiente fora, a umwelt que envolve o quarto onde ela escreve e a stimmung no modo como fantasia o encontro. Em As mãos negativas fazemos um passeio de carro pelas ruas de Paris ao amanhecer enquanto ouvimos um poema sobre as marcas de mãos encontradas nas cavernas pré-históricas do sul da França. Durante a trajetória vemos uma cidade sombria acordando aos poucos de um sono profundo. Césarée nos mostra imagens de andaimes de obra em torno de uma grande escultura de um busto feminino, sonorizada por uma trágica história de amor e de guerra.

Duras filma o recorte, a fenda dos interiores sensíveis, cria espaços integrando narrativa, memória, paixão, impossibilidade, vida e morte. Seus planos e sequências seguem em ritmo persistente, sobrepondo e contrapondo paisagens (interiores e exteriores) e sentidos. O espectador percebe a história nas entrelinhas, nas nuances das vozes que falam alienadas da imagem, vindas não se sabe de onde, desconhecidas.

7 Termos constantes nos Conceitos Fundamentais da Poética de Emil Staiger (1997). 


\section{Corpo: lugar do silêncio}

$\mathrm{Na}$ dança não podemos deixar de observar os processos de configuração e desconfiguração da forma expressiva inscrita no espaço. Produtor e suporte desta linguagem, o corpo organiza as conexões psicomotoras que ocorrem no espaço mental da memória, da imaginação e da realidade e gera ações significativas de seu modo de estar/ pensar no mundo. Essas combinações se tornam visíveis no momento em que o silêncio (do movimento) se instala modificando o estado presente como código pré-estabelecido e desfazendo o esquema de seus padrões cotidianos. Nesse lugar entre presença e esquecimento, a cena emerge da tensão gerada entre o corpo atravessado pela impressão sensorial e sua resposta motora ao espaço, cuja impulsão é o desejo e a necessidade de dizer algo por meio da linguagem do movimento.

O processo criativo de preparação corporal, montagem coreográfica e montagem das sequências do filme, se concentrou em transportar as sensações das imagens literárias e fílmicas para o movimento produzindo, a partir de provocações cinestésicas, da leitura, da análise e da decupagem dos textos e dos planos, composições de doze minutos para cada um dos sete episódios: Abertura; Invasão marítima; Resíduos; Deambulação (ou Correntes Profundas); Vórtex; Adágio; Thalassa (ou A Dissolução).

As personagens de M. Duras são, na sua grande maioria, mulheres marcadas pela solidão e pela perda, que apresentam sintomas comuns em um estado de ausência e deambulação como se não pertencessem ao meio que as cerca, divagam sobre lembranças e reúnem os resíduos de suas próprias histórias. Dentre a vasta galeria de mulheres esquecidas de si, destacam-se no filme: Lol V. Stein do romance O Des/umbramento (1964); Anne-Marie Stretter e a Mendiga de Savannah Kets do romance $O$ Vice-Consul (1965) e do filme India Song (1975); Aurélia Steiner dos filmes Aurélia Steiner Vancouver e Aurélia Steiner Melbourne (1979); Marie Donnadieu, a mãe de Uma barragem contra o Pacífico (1958);
Theodora Kats, de uma história que jamais poderia ser escrita, contada em Yan Andréa Steiner (1992); e o homem de Homem Sentado no corredor (1980).

No filme Enquanto caem as folhas... (2015) as personagens citadas acima aparecem fora de seus contextos originais em um espaço cênico devastado, depois de sofrerem uma invasão marítima. Presas na caixa preta entre memória e devaneio, procuram insistentemente retomar suas histórias inacabadas.

A estrutura coreográfica das personagens escolhidas foi construída a partir do levantamento do que restou de suas histórias. Para isso, depois de cada livro lido e de cada filme visto e revisto, de terem sido destacadas qualidades específicas de cada uma, surgiu a questão que envolveria a motivação interna e a iniciação do movimento nesta nova condição geográfica do filme. Não procuramos o movimento que seria natural da história de cada uma, mas aquele que indicaria o traço característico determinante de sua sobrevivência. Então indagamos: o que permaneceria pulsando com vida, quando se perde, inclusive, a identidade e a noção de si? O que em nós sobrevive a revelia da nossa consciência e que nos mantém vivas, apesar de qualquer coisa? Seriam os ritmos primitivos de nossas necessidades fisiológicas e psicológicas encontrados nos padrões de desenvolvimento do movimento humano? Como expressar esses ritmos?

Para dar conta dessas questões sobre ritmos orgânicos, sintomas e suas manifestações corporais recorremos a Teoria dos Esforços de Rudolf Laban e aos estudos sobre os padrões de desenvolvimento do movimento e seus respectivos ritmos da Dra. Judith Kestenberg e Irmgard Bartenieff, investigando na variação gestual o modo como as personagens poderiam ser reconfiguradas. Com essas questões em mente, procuramos na atmosfera da umwelt, a praia imensa e deserta em contraste com o mosaico dos nichos acumulados na caixa preta do espaço cênico, formas dinâmicas de expansão e confinamento que, associadas aos Ritmos de Tensão de Fluxo (RTF) de Kestenberg, determinam a pulsação rítmica da stimmung, ou dinâmica da at- 
mosfera individual que emana de cada uma das personagens confinadas em seus nichos. Experimentando os RTF e projetando-os no espaço foi possível encontrar os gatilhos e os meios de acesso aos estados expressivos em que o corpo revira-se alheio as fronteiras e a sua própria cartografia.

A ideia de que o movimento humano pode ser pensado como uma forma arquitetônica viva na qual a Força de Gravidade, as tensões espaciais e a intensidade da energia cinética se harmonizam, compõem a Kinesfera $(\mathrm{K})$ de Laban: a esfera do espaço individual de movimento sustentada pela estrutura tridimensional do corpo, composta por três dimensões de altura, largura e profundidade conectadas ao centro de gravidade e suas extremidades. $O$ tamanho da $\mathrm{K}$ define o alcance do gesto gerando uma forma de comunicação que processa estímulos externos, incorpora, relaciona e expressa intenções.

O que compõe o sentido dinâmico e expressivo das mudanças da forma na esfera individual de movimento, em que corpo e espaço misturam-se um no outro, é o modo como a energia cinética é impulsionada à ação, combinando-se com outros fatores do movimento. Livre ou Condensado, o Fluxo é aquele que define a progressão do movimento e que revela o ritmo respiratório de uma emoção. Explorar criativamente as possibilidades expressivas da $\mathrm{K}$ significa permitir a fluidez da energia cinética para que as conexões corporais aconteçam sem uma ordem externa arbitrária ou outra pré-instalada nos padrões de desenvolvimento motor. As interseções entre sensação, percepção, imaginação criativa e imaginação reprodutora (armazenadas na memória) interferem no sistema neuromuscular desencadeando as conexões funcionais e expressivas das formas corporais. As cadeias musculares organizam ritmicamente a intensidade do fluxo na trajetória da energia cinética e impulsionam o movimento para o espaço fora do limite corporal, comunicando-se com o mundo.

Por essa via cinestésica, a dança (linguagem poética do movimento) proporciona àquele que a contempla a experiência de participar da criação de um evento erguido pelos traços pessoais da movimentação humana e de reconhecer suas próprias características corporais de conexão. Para o bailarino, as variações composicionais da forma expressiva e sua evolução no espaço acontecem na medida em que a percepção dos estímulos externos mapeiam as trajetórias fluidas da energia cinética ligando o aparelho psicomotor à estrutura espacial. Trata-se de uma fisiologia da expressividade. Os pilares dessa obra arquitetônica em ação são constituídos por grandes Temas de Transformação Dinâmica do Movimento, principalmente no contexto interno/externo do reviramento da Banda de Moebius. Nesse momento, tensões espaciais e imagens corporais se encontram, se transpassam e se equilibram produzindo uma série de transformações no modo como as formas são configuradas no território desconhecido do silêncio onde se criam, lugar comum na manifestação de sintomas.

A expansão ilimitada de uma ação em Fluxo Livre pode representar o abismo interno que encontramos na movimentação de alguma personagem, como a sensação de estar em queda livre, por exemplo. Ali não existe mais a separação entre mundo interior e a manifestação externa, mas sim um volume em Forma Fluida, sem contorno nítido, um corpo deslizante, sem moldura, que funciona como suporte de emoções. Um corpo-inscrição em verso e reverso que como um prisma refrata a dinâmica dos afetos e os projeta no espaço.

A Dra. Kestenberg ${ }^{8}$ detectou em seus pacientes infantis uma linguagem de movimento construída por padrões rítmicos relativos aos padrões de de-

8 A Dra. Judith Kestenberg (1910-1999), psiquiatra e psicanalista formada pela escola de Viena, criou um sistema de investigação psiquiátrica, o Kestenberg Movement Profile (KMP) estruturado como um método que traça um perfil psicológico por meio da anotação e grafia do movimento corporal de um indivíduo. Este sistema está organizado sobre duas linhas de desenvolvimento humano: o Sistema I, focado na linha da Tensão de Fluxo e de Esforço descrevendo a dinâmica do movimento e o Sistema II, analisa a linha de desenvolvimento moldada pelo Fluxo de Forma que descreve o desenvolvimento relacional e a estrutura de movimentos. (TURTELLI; TAVARES, 2008). Disponível em: http://www.kestenbergmovementprofile. org/. Acesso em: 05 jun. 2020. 
senvolvimento humano. Tais ritmos pulsam no corpo embrionário e se desenvolvem durante toda a vida do indivíduo. Os RTF expressam necessidades fisiológicas e desejos predominantes nas fases oral, anal, uretral e genital, apontadas por S. Freud, assim como a dinâmica dos Esforços e Pré-esforços de Laban (Peso, Tempo, Espaço e Fluxo) dependem da necessidade e do desejo de algo. Essas dinâmicas podem ser alteradas pela intensidade e circulação dos fluidos nos sistemas corporais, assim como o fluxo emocional revela-se conectado à respiração. É nesta tensão entre os meios externos e internos que tais ritmos se manifestam intuitivamente ora indulgentes ora resistentes. Consecutivamente se destacam nas fases: oral (sugar/morder); anal (enrolar/reter-soltar); uretral (escorrer/começar-parar); genital interna (balançar/ondular) e genital externa (pular/ ejetar). Do ponto de vista da expressividade, a falta ou a permanência em um padrão rítmico se apresenta nas frestas do movimento, revelando importantes aspectos em pequenos gestos inconscientes.

Segundo Freud, vivemos em dois planos: o da realidade e o do inconsciente (chamado de "a outra cena") que se manifesta no sonho, nos sintomas, nos atos falhos e nos chistes. As variações dos sintomas se multiplicam e as variações da definição do sintoma também. O sintoma seria a expressão corporal do acontecimento inconsciente que contém um sentido, que conta uma história criada por um sujeito. Para Freud, o sintoma varia, mas um tema permanece e se repete: o sexual.

Os sintomas são a manifestação de uma insatisfação ou de algum desejo sexual reprimido, ou medidas para impedir tal satisfação e via de regra têm a natureza de conciliação, de formação de compromisso entre duas forças que entraram em luta no conflito: a libido insatisfeita, que representa o recalcado e a força repressora, que compartilhou de sua origem. É esse acordo entre as partes em luta que torna o sintoma tão resistente. (DIAS, 2006, p. 400).
Para Lacan, o sintoma é da ordem da letra, da palavra e do símbolo, que se revela como uma marca da linguagem. Na dança é o corpo que expressa a linguagem do movimento, onde se formam os símbolos e se produzem os desejos e também onde se escondem os recalques ${ }^{9}$. Por essa via, na obra de Marguerite Duras, como num espelho, as personagens se configuram e se multiplicam refletindo a "outra cena" delas mesmas. A deambulação aparece nas ações como o sintoma comum a todas elas cujos nomes e histórias atravessam solitárias um extenso território mental, muitas vezes representado pelo mar, por florestas, espaços vazios, escuros ou ensolarados.

O elenco iniciou, então, a exploração de movimento em seu grau zero, no lugar do silêncio no corpo, e escolheu deambular como meio de acesso aos Sistemas Fluidos, aos RTF e as combinações de Esforço, fazendo vir à tona através do movimento, as vozes das personagens escolhidas com suas características individuais e de sobrevivência. As frases coreográficas desenvolvidas a partir das variações e intensidades de Fluxo acrescentaram extrema qualidade sensitiva à cena, tornando as dinâmicas dos Esforços combinados em Estados e Impulsos condutoras de todo o filme.

9 Teóricas francesas, influenciadas pelo pensamento de Jacques Lacan, enfocam a linguagem como principal ferramenta para o progresso e a organização social, pelo fato da linguagem possuir um viés inerentemente masculino na sociedade patriarcal. Partindo da distinção feita por Lacan entre o mundo do imaginário (visto como pré-linguístico) e o mundo do simbólico (a ordem baseada na linguagem), essas teóricas sustentam que o discurso feminino é impossível de ser dito ou escrito já que "as muIheres foram forçadas a encontrar seu lugar dentro de um sistema linguístico essencialmente estranho a elas, que linear e gramaticalmente ordena o simbólico, o superego e a lei" (KAPLAN, 1995, p. 136). 
Figura 2 - Lol. V. Stein: Ana Figueiredo.

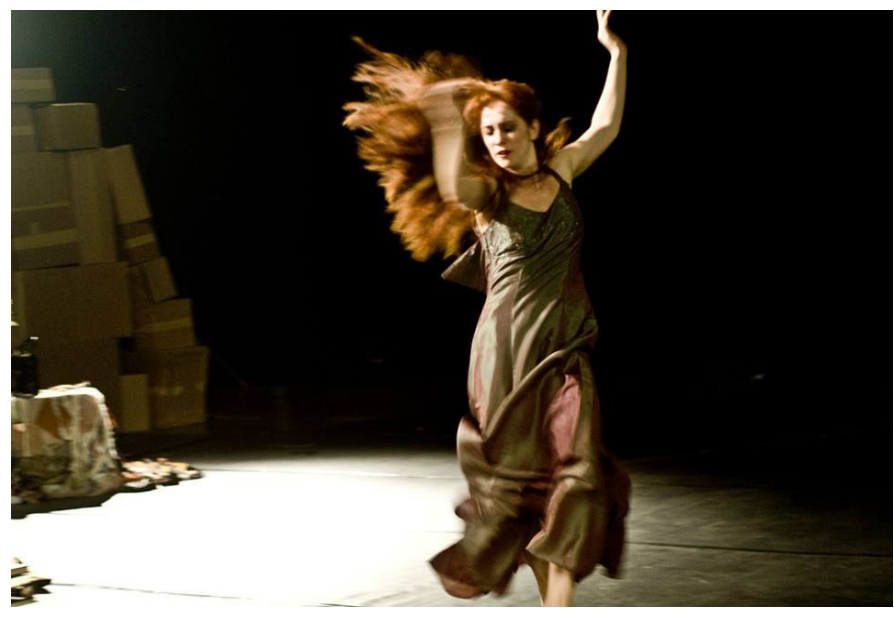

Fonte: Foto de Still: Marina Pachecco. Salão Helenita Sá Earp, Ilha do Fundão, 2012.

Sobre a personagem central do romance Le ravissement de Lol V. Stein, traduzido como O deslumbramento, a autora disse não pensar mais na jovem Lol, de quinze anos, não pensa mais em seu grito, o de nascimento da sua escrita. Numa certa medida a história de Lol desencadeia uma série de outras histórias e seu grito se repete nelas como um detonador. A escrita é o próprio sintoma da escritora: o grito de um amor impossível e inominável. Ainda adolescente Lol foi abandonada durante o baile do Cassino de S. Thala por seu noivo tomado de um amor fervoroso por uma desconhecida. A jovem sofreu calada a dor que a paralisou, mantendo-se ausente das emoções do mundo. Dez anos depois voltou a morar em T. Beach, casada e com filhos, sem demonstrar qualquer traço do trauma. Entretanto, o amor inominável foi o marco que desencadeou a trama e suspendeu a vida da personagem. Mais tarde ela procurou desesperadamente retomar a cena para revivê-la e desde então adquiriu o hábito de caminhar incansavelmente durante as noites à procura de $\mathrm{S}$. Thala:

Aqui é S.Thala até o rio, e depois do rio é ainda S.Thala, o lugar de todo o amor. O baile tremia ao longe, único destroço de um oceano agora tranqüilo, na chuva em S. Thala. Ela protege-o, alimenta-o. Ela penetra nele. Penetra todos os dias. Vê cada vez de maneira mais precisa, clara, o que quer ver. O que reconstrói é o fim do mundo. (DURAS, 1986a, p. 33-34).

Figura 3 - Anne-Marie Stretter: Fernanda Santana.

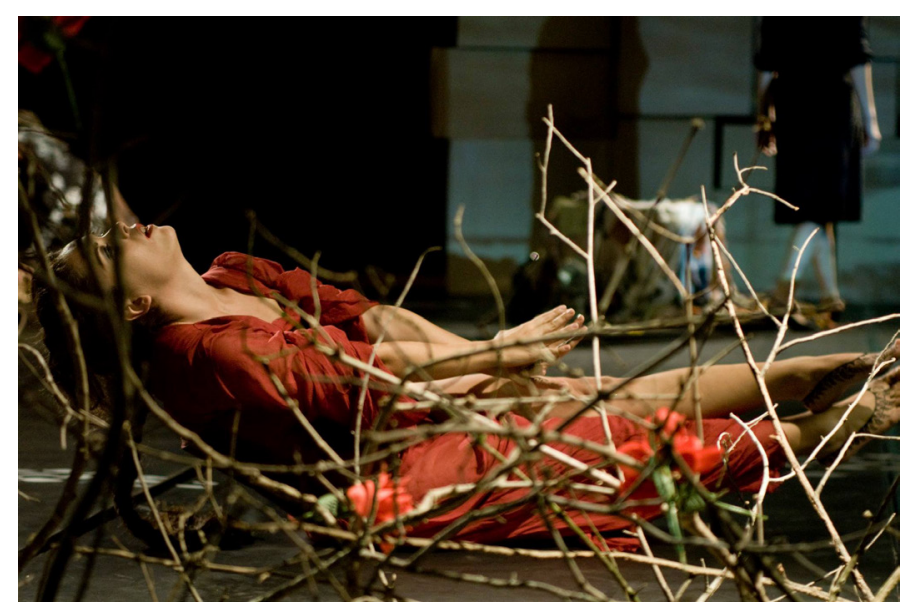

Fonte: Foto de Still: Marina Pachecco. Salão Helenita Sá Earp, Ilha do Fundão, 2012.

A figura de Anne-Marie Stretter carrega o mistério, a escuridão e a luz correspondentes à imagem da mulher-fatal como vista nas ficções do início do século XX e de cada uma delas o traço da prostituta sagrada, da destruição e da morte. Linda e silenciosa aparece como pivô da cena do baile de S. Thala que desencadeou o sintoma de Lol. Sua presença espectral mistura sensualidade e distanciamento e vagueia num tédio absoluto, não demonstrando nenhuma reação ao que ocorre ao seu redor. Representa uma história de amor imobilizada no clímax da paixão e envolta dela outra história de horror, fome e lepra misturados na umidade pestilenta do verão. Diferentemente de Lol, Anne-Marie fica impassível, imóvel como morta em meio às festas da embaixada francesa, indiferente aos homens apaixonados, conectada ao canto longínquo da Mendiga, à lepra, ao grito, à loucura do Vice-Cônsul de Lahore e ao suicídio de Michael Richardson (o noivo que abandonou Lol V. Stein no baile).

Duras especifica em nota introdutória da publicação do texto India Song (1973) pela Gallimard, que o uso de vozes soando de fora da cena, experimentado no filme La Femme du Gange (1973), 
proporcionou movimentar a narrativa para o esquecimento deixando-a disponível a outras memórias além das do autor. Memórias estas que fazem parte paralelamente de qualquer outra história de amor. Memórias deformantes, criativas, diz ela, outra vez levadas para outro filme Son nom de Venice dans Calcutta désert, realizado em 1976, que por sua vez reproduz a banda sonora de India Song e mostra a destruição completa das personagens, do filme pelo filme, do texto. Não só as memórias atravessam as histórias e os suportes, mas as personagens principais desse ciclo texto-filme-texto: Lol V. Stein, Anne-Marie Stretter e seu duplo (a Mendiga de Savannakhet), estão como origem ou ponto zero da escritura que desdobram outras.

O que eu não disse é que todas as mulheres de meus livros, seja qual for sua idade, decorrem de Lol V. Stein. Quer dizer, de um certo esquecimento delas mesmas. Todas têm olhos claros. Todas são imprudentes, imprevidentes. Todas elas transformam suas vidas numa desgraça. Estão muito amedrontadas, têm medo das ruas, das praças, só esperam que a felicidade venha até elas. Todas as mulheres dessa procissão de mulheres dos livros e dos filmes se parecem, desde La femme du Gange até esse último estado de Lol V. Stein. (DURAS, 1989, p. 29).

A construção física de Lol parte da constelação dos ritmos emocionais, os RTF. Suas ações predominantes são deambular, deslumbrar, gritar e desmaiar que vão sendo refeitas a cada novo trajeto realizado no palco com novas dinâmicas e intensidades na passagem de um ritmo a outro e de um episódio a outro. Lol caminha em direção ao passado, ao impossível, à procura da cena perdida e do desejo desconhecido. Lol, a única que se desloca pelo espaço, segue deambulando em Estado Móvel (Fluxo/Tempo). Anne-Marie, por sua vez, representa uma afogada que se debate nas variações do Estado Onírico (Fluxo/Peso), enquanto a Mendiga de Savannakhet, como seu duplo deambula por todas as locações e tem como missão conduzir o olhar do espectador para a infinitude do filme.
Figura 4 - A mendiga de Savannakhet: Marta Bonimond.

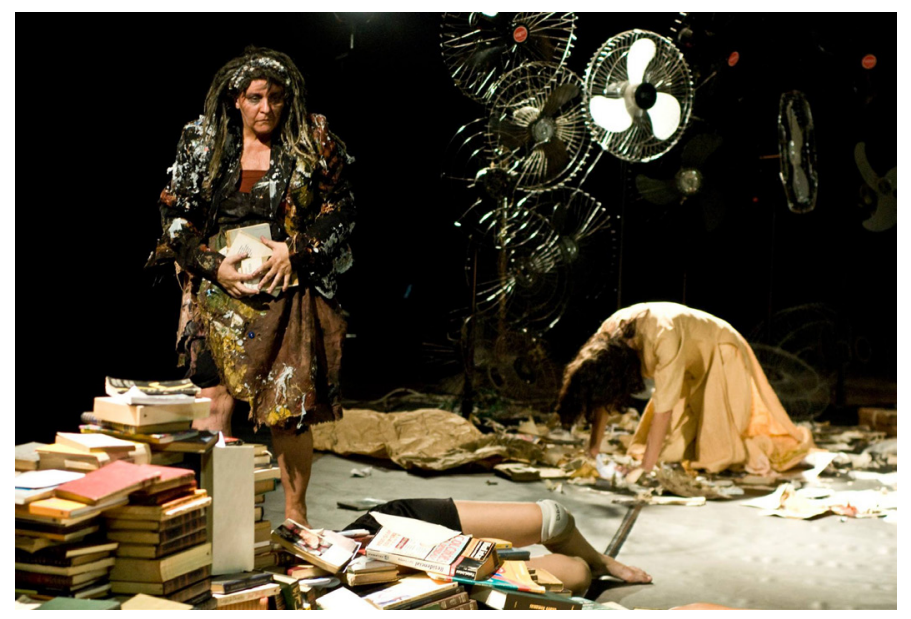

Fonte: Foto de Still: Marina Pachecco. Salão Helenita Sá Earp, Ilha do Fundão, 2012.

Marie Donnadieu, a Mãe, personagem de Barragem contra o Pacífico, representa a própria mãe de Duras e sua infância na Indochina. Sua história é triste: viúva com três filhos perdeu tudo o que tinha por sucessivas invasões marítimas que destruíram sua plantação de arroz, ela foi passada para trás. As terras além de salobras não valiam nada, assim como o dinheiro que havia guardado também não. Desde então a Mãe apresentou sintomas de alienação perdendo a noção de espaço e catatonia. Desse modo suas ações coreográficas se configuraram no Impulso Apaixonado, combinando os fatores de Fluxo/Peso/Tempo. Seguem alguns trechos retirados do livro sobre a mãe: 
Figura 5 - A mãe Marie Donnadieu: Luciana Bicalho.

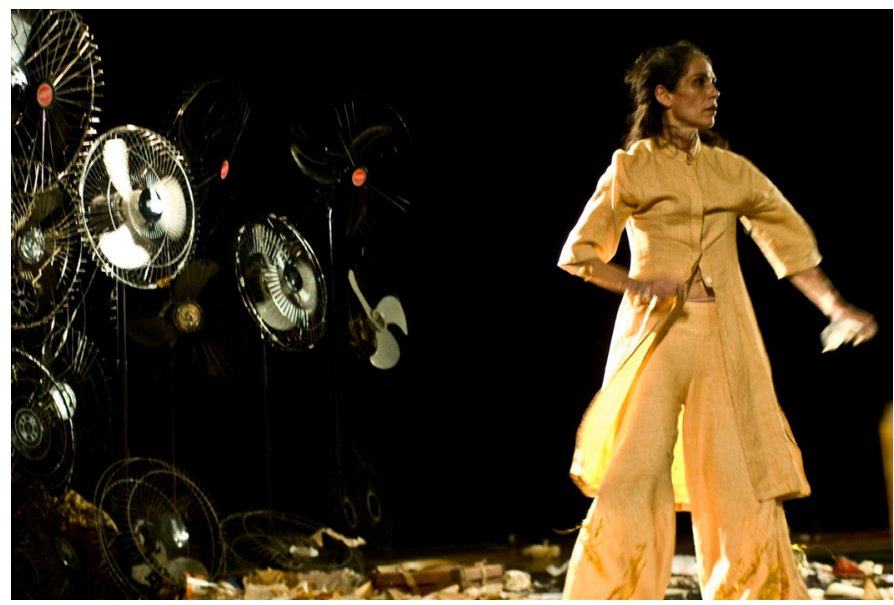

Fonte: Foto de Still: Marina Pachecco. Salão Helenita Sá Earp, Ilha do Fundão, 2012

A Mãe viveu sem àquela paciência, àquela pausa que é servida à mãe como uma benção....Carregou sua paixão sozinha, sem nenhuma temperança, com uma violência jamais saciada... Quisera alargar o Pacífico. Sofrera inundações tais, que a transformaram num monstro devastador, com poderosos encantos. A vida era terrível e a mãe tão terrível quanto à vida. Tinha se resignado por fim a todas as suas derrotas. Um rosto desmembrado, repartido entre a expressão de um cansaço inumano e de um prazer não menos extraordinário, não menos inumano. Imersa nas profundezas, flutuou. Fora sua esperança infatigável, incurável, que fizera dela àquilo que se tornara: uma desesperada da própria esperança. Chorou violentamente, chorou como nunca tinha chorado antes, como se finalmente e para sempre, descobrisse a dor. (DURAS, 2003).

Para Aurélia Steiner o trabalho consistiu na transposição direta do texto e da paisagem fílmica em dança. Sua história nasceu como filme-poema em 1979. A jovem de 18 anos, escreve desesperadamente, se multiplica em outras, habita lugares diferentes. É a judia errante, solitária e desterritorializada como sua autora. Ela também fala de um amor devastado pela guerra. Não temos a descrição de sua figura e contamos com a imaginação para fazê-la existir em cena. Desse modo partimos do que ela diz de si, da sua $\mathrm{K}$ (esfera individual) misturada à do filme e do que descreve a sua volta. Aurélia Steiner escreve suas cartas no ar em Impulso Visual combinando Fluxo, Tempo e Espaço enquanto a outra Aurélia, em Estado Rítmico de Peso e Tempo, apaga as marcas deixadas pelas palavras em sua pele.

\section{Figura 6 - Aurélias: Daniela Magalhães}

\section{e Taíla Borges.}

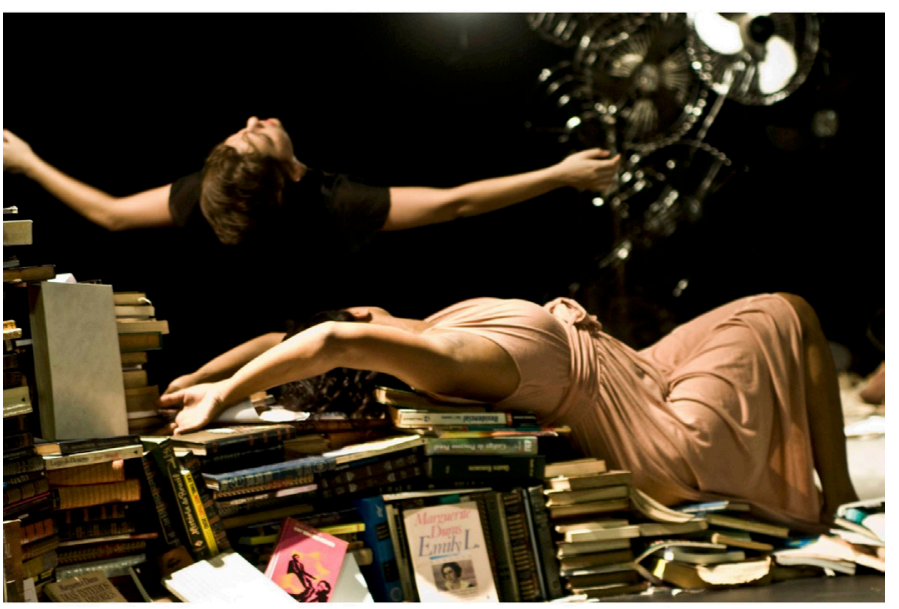

Fonte: Foto de Still: Marina Pachecco. Salão Helenita Sá Earp, Ilha do Fundão, 2012.

Theodora Kats foi uma jovem judia que esperou ser resgatada, durante muito tempo em uma estação de trem, na Alemanha, na Segunda Grande Guerra. Esperava o trem dos judeus... Sem a noção de tempo, a personagem se manteve em espera no Impulso Mágico (Fluxo/Peso/Espaço) desenhando seu rosto em todas as superfícies que encontrava. Os outros personagens que aparecem como o Homem e o Coro das Gaivotas servem como suporte e estão em contraponto com as mulheres. Atuam no impulso e na concretude das Ações Básicas de Esforço, condensadas, que combinam os fatores de Peso, Tempo e Espaço. A Criança, ou a Gaivota Mirim, representante da esperança, circula pelo espaço em revoadas do Estado Remoto, Fluxo-Livre e Espaço-Indireto. O coro inicial de Leitoras em torno da árvore caminha initerruptamente enquanto lê a obra de Marguerite Duras, em Estado Onírico combinando Fluxo e Peso. 
Figura 7 - Theodora Kats: Tatiana de Faria; Anne-Marie Stretter: Fernanda Santana; Savannakhet: Marta Bonimond.

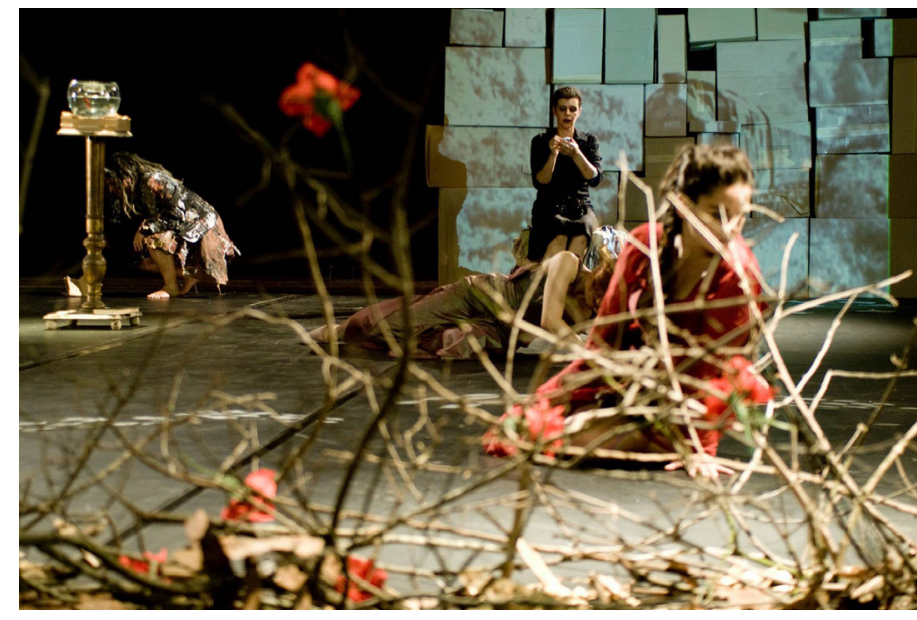

Fonte: Foto de Still: Marina Pachecco. Salão Helenita Sá Earp, Ilha do Fundão, 2012.

O desafio proposto foi inscrever as imagens e as sensações da linguagem escrita no corpo dançante, para apresentar os sintomas nas formas fluidas do silêncio, do abandono, do deslumbramento e do desejo, como as pacientes que deambulam descritas por Edmar Oliveira: "Os corpos se movimentam com a determinação aparente de quem sabe onde está indo. Numa direção. Em sentido contrário, com a mesma determinação, como se a volta fosse a continuação da ida. Outros corpos como a se deixar levar, como plumas ao vento." (OLIVEIRA, 2009, p. 117).

\section{A montagem e os episódios}

A dinâmica da composição musical impulsionou a montagem construindo uma narrativa não linear distribuída em sete movimentos. O corte final corresponde a uma coreografia configurada no formato de uma suíte musical disposta como um mosaico. As partes, embora independentes, não devem ser colocadas em ordem aleatória, uma vez que cada movimento desenvolve um sentido rítmico fechado em si mesmo e são ligados por um fio condutor que mantém a coesão dramatúrgica. Há elementos de transição retirados do vocabulário da dança e do cinema na condução dos frames, seguindo o fluxo interno ao modo de Tarkovski (2010)10 e a composição da forma sugerida por Eisenstein (2002)11.

A Abertura apresenta os elementos que dão o tom do filme, como a árvore e as folhas que caem, o círculo de leitoras que andam em volta da árvore do conhecimento, o livro que projeta personagens e a caixa de filme de onde surge uma pequena Pandora. A corrida em bandos de mulheres remete ao coro grego, as Eríneas e as mulheres em geral, seria um bando de "gaivotas". Savannakhet conduz o espectador para dentro da história durante sua deambulação pelo mundo, representado por uma praia imensa e deserta.

A Invasão Marítima começa nesta mesma praia com uma grande onda que invade a tela cobrindo tudo, o som é de mar, de gaivotas e gritos femininos. O livro, a câmera, a personagem submergem na caixa preta, mostrando o que sobrou do refluxo da onda: o interior devastado. No espaço cênico vemos nichos e corpos caídos à revelia, abandonados, esquecidos, como Resíduos da vazante. Aos poucos esses corpos tentam se erguer e se recompor ao som de um violão solo que se mistura com o som de um trem em movimento, começamos a identificar as personagens.

10 Andrei Tarkovsky (1932-1986), importante pensador russo, foi cineasta, diretor de teatro, escritor e teórico do cinema. É considerado um dos maiores e mais influentes diretores da história do cinema russo e mundial. Seus filmes exploraram temas espirituais e metafísicos, e são conhecidos por seu ritmo lento e longas tomadas, imagens visuais oníricas e preocupação com a natureza e a memória. Disponível em: https://en.wikipedia.org/wiki/ Andrei_Tarkovsky. Acesso em: 08 ago. 2020.

11 Serguei Eisenstein (1898-1948) foi um dos mais importantes cineastas soviéticos. Relacionado ao movimento de arte de vanguarda russa, participou ativamente da Revolução de 1917 e da consolidação do cinema como meio de expressão artística. Notabilizou-se por seus filmes mudos: A Greve, O Encouraçado Potemkin e Outubro, assim como os épicos históricos Alexandre Nevski e Ivan, o Terrível. Sua obra influenciou fortemente os primeiros cineastas devido ao seu uso inovador de escritos sobre montagem. Disponível em: https://pt.wikipedia.org/ wiki/Serguei_Eisenstein. Acesso em: 08 ago. 2020. 
Figura 8 - Gaivotas: Dandara Ventapane, Andrea Pimentel, Geise Regatto, Elli Sza; A Mãe: Luciana Bicalho.

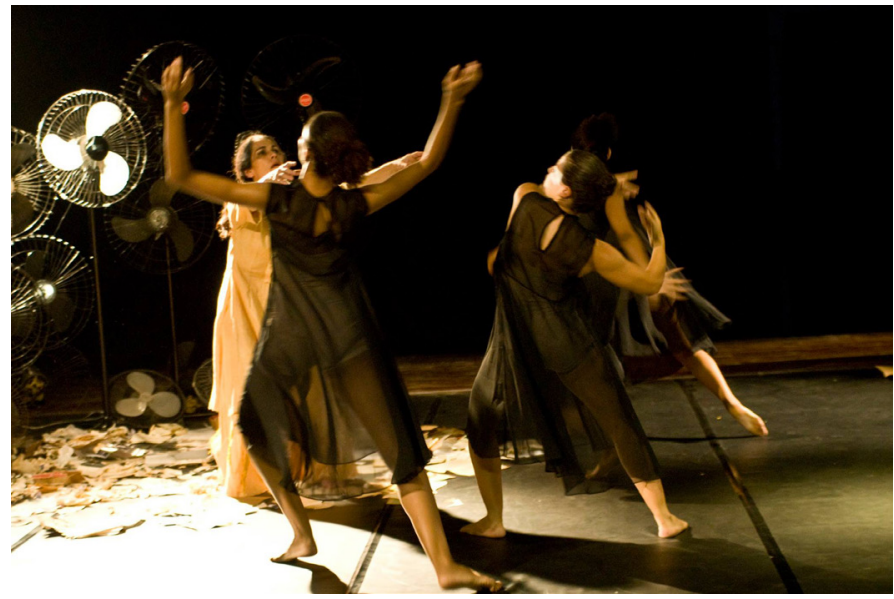

Fonte: Foto de Still: Marina Pachecco. Salão Helenita Sá Earp, Ilha do Fundão, 2012.

Em Deambulação, o som grave de um quinteto de cordas mantém uma pulsação constante derivada da frequência do mesmo trem que avança mais lentamente e nunca chega, provocando o adensamento do tempo e o condensamento do fluxo do movimento. Expõe, pelo olho da câmera, o desejo latejante daquelas mulheres, quando nos coloca muito próximos de seus corpos, de sua pele, de seus poros. Em seguida, o Vórtex explode e multiplica as figuras que expressam em repetição cíclica suas neuroses e pulsões. As personagens em frenesi entram na vertigem da exaustão abandonando o quadro ou em sucessivas quedas.

O Adágio acalma os sentidos e promove a recuperação do controle, a cena então escorre de volta para o mar, de volta para Thalassa. Na praia, a figura da Mãe se desfaz na areia, enquanto O casal de O Homem sentado no corredor permanece na praia.
Figura 9 - O Homem sentado no corredor: Ciro Figueró e Taíla Borges.

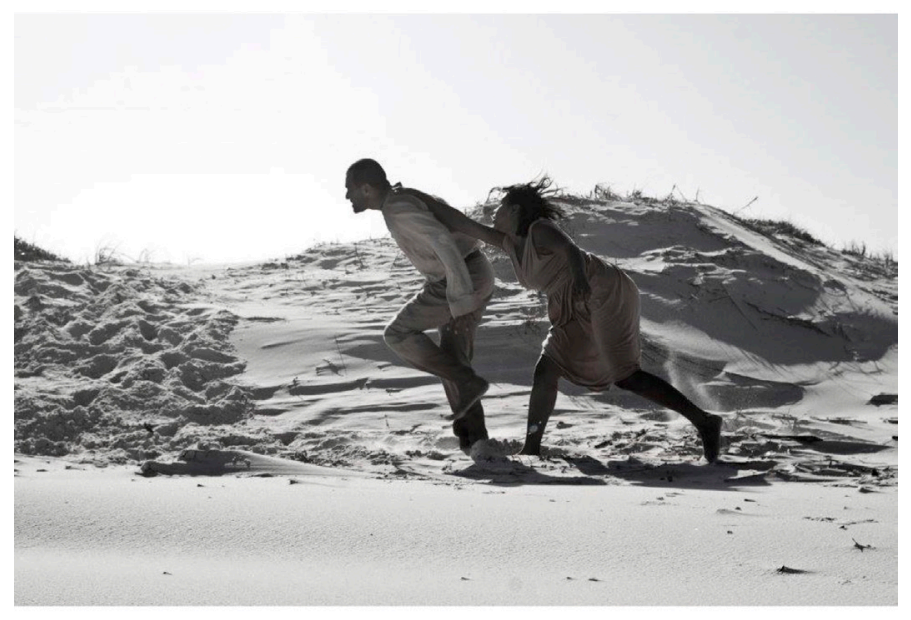

Fonte: Foto de Still: Marina Pachecco. Praia Grande, Arraial do Cabo, RJ, Julho 2012.

Anne-Marie nos carrega para as profundezas, correndo em direção à brancura da fenda oceânica, onde é possível chegar, mas da qual, jamais se poderá sair. O lugar onde todas se perderam, a estação na qual o trem jamais passará para levá-las de volta à superfície. Quem desenrola essa história é a Mendiga de Savannakhet que segue andando, sempre adiante, pela praia, rumo ao infinito. 
Figura 10 - A Mendiga de Savannakhet: Marta Bonimond.

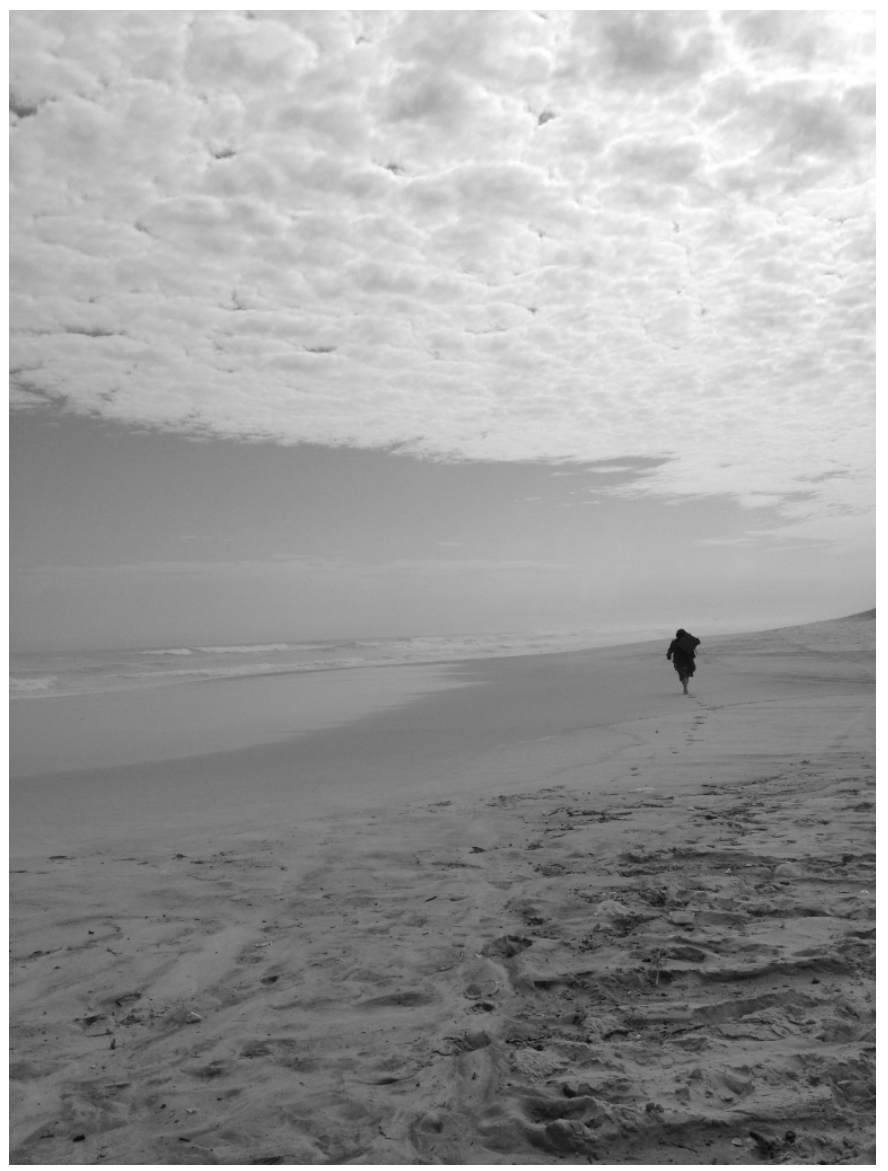

Fonte: Foto de Still: Marina Pachecco. Praia Grande, Arraial do Cabo, RJ, Julho 2012.

\section{Considerações finais}

O filme, enquanto resultado artístico, expressa a sensação de ter cumprido seu desafio inicial, de trazer para o corpo, os perfis psicológicos das personagens de Marguerite Duras, que atravessam extensos territórios mentais. As características desses estados corpóreos de silêncio, dor, abandono, deslumbramento, desejo, tédio, loucura, foram identificadas através da experimentação dos padrões de desenvolvimento e seus ritmos de fluxo, que, combinados às variações dos fatores de qualidade do movimento, geraram as frases individuais de movimento.

Os territórios mentais dessas personagens, aparecem representados, tanto pelo mar e pela praia imensa, quanto pelo espaço cênico entulhado de objetos. Neles, personagens, sequências e músicas, movem-se pela banda de Moebius12. Segundo Monteiro (2014), a topologia é uma forma tridimensional, sem limite e sem fronteiras. Uma continuidade sem fim, e a banda de Moebius, o objeto topológico que representa a estrutura do sujeito. O espaço topológico é então definido como o espaço do sonho, da criação e da invenção, assim como contém a dinâmica do ir e vir, fazer-desfazer, construir-destruir. O espaço da troca constante, do inesperado, do vazio, da falta, do dentro que passa para a superfície e vice-versa. O lugar do confuso, do incompreendido e do pouco nítido, que pretende evitar nossa compreensão, para nos abrir a uma outra forma de pensar, de um saber incompleto, em andamento constante (MONTEIRO, 2014).

Tomada como a principal topologia na composição estrutural do filme, desde o roteiro até o corte final, a banda de Moebius aparece na deambulação das personagens, na ordem repetitiva no interior das sequências, nas músicas, como também no próprio título do filme, Enquanto caem as folhas... O que vemos deslizar por esses anéis, não distingue o que vem de dentro do que se mostra fora, nem aquilo que pertence ao fundo e o que aparece na superfície. $O$ que podemos perceber é que o sentido cinestésico faz reverberar em nós as intensidades das ações e, à medida que percebemos as sensações do movimento, posto na tela, identificamo-nos como essenciais à troca, procurando o contato com o outro. $\mathrm{O}$ diferencial da dança é que ela toca a pele do espaço.

12 O psicanalista Jacques Lacan (1901-1981) encontrou na banda, ou anéis de Moebius um importante recurso metafórico para interpretar a estrutura do aparelho psíquico. A figuração do aparelho psíquico em sua dimensão topológica criou uma descontinuidade na tradição filosófica ocidental desde Platão até Hegel pois instaurou a possibilidade de apreender o psiquismo para além da clássica dicotomia entre corpo (soma) e alma (psykhé), mundo sensível e mundo inteligível, exterior e interior, fora e dentro. (MARIGUELA, 2010). Disponível em: https://marciomariguela.com.br/banda-de-mobius/. Acesso em: 03 ago. 2020. 
Equipe de criação de Enquanto caem as folhas... (2015):

Concepção, Roteiro, Direção: Marina Martins

Direção de Fotografia e Câmera: Gilberto Otero

Direção Musical e Composição: Miguel Martins

Direção de Arte e Figurino: Reinaldo Elias

Edição de imagem: Marina Martins e Fernanda Sant'Ana

Coreografia: Marina Martins e Elenco

Elenco: Luciana Bicalho, Tatiana de Faria, Marta Bonimond, Fernanda Sant'Ana, Taíla Borges, Daniela Magalhães, Ana Figueiredo, Ciro Figueiró

Gaivotas: Andreia Pimentel, Dandara Ventapane, Elli Sza, Geyse Regato

Leitoras: Berenice Xavier, Bruna Fiúza, Christine Junqueira, Inês Saraiva, Lígia Tourinho

Coro: Aeda Mafalda, Carolina Gambine, Carolina Boanova, Cíntia Siqueira, Daliana Marques, Daniela Moraes, Eliza Lopes, Elizete Oliveira, Flávia Cruz, Flora Bulcão, Gabriela Jung, Gizele Alves, Laís Castro, Marcia Paulino, Rosana Oliveira

Participações Especiais: Juca Barros, Laura de Faria, Natália Kochem

Voz India Song: Kelly Benevides.

\section{Referências}

DIAS, Maria das Graças Leite Vilella. O sintoma: de FreudaLacan. Psicologia em estudo. Maringá, v.11, n. 2, p.399-405, mai/ago. 2006. Disponível em: http://www. scielo.br/pdf/pe/v11n2a18.pdf. Acesso: 2/05/ 2011.

DURAS, Marguerite. O Deslumbramento. Tradução de Ana Maria Falcão. Rio de Janeiro: Nova Fronteira, 1986a.

DURAS, Marguerite. A Vida Material. Tradução de Heloísa Jahan. Rio de Janeiro: Globo, 1989.

DURAS, Marguerite. Escrever. Tradução de Rubens Figueiredo. Rio de Janeiro: Rocco, 1994.
DURAS, Marguerite. Barragem contra o Pacífico. São Paulo: Arx, 2003.

DURAS, Marguerite. O Amante. Tradução de Aulyde Soares Rodrigues. Rio de Janeiro: Nova Fronteira s/d.

DURAS, Marguerite. Cadernos de Guerra e outros textos. Tradução de Mário Laranjeira. São Paulo: Estação Liberdade, 2009.

EISENSTEIN, Serguei. A Forma do Filme. Apresentação, notas e revisão técnica: José Carlos Avelar. Tradução de Teresa Ottoni. Rio de Janeiro: Jorge Zahar, 2002.

FERNANDES, Ciane. Esculturas Líquidas: a Pré-Expressividade e a Forma Fluida na Dança Educativa. Cadernos Cedes, ano XXI, no 53, abril/2001.

FERNANDES, Ciane. O corpo em movimento: o sistema Laban/Bartenieff na formação e pesquisa em artes cênicas. 2a ed. São Paulo: Annablume, 2006.

FERNANDES, Ciane. Princípios em movimento na pesquisa somático-performativa. Resumos do Seminário de Pesquisas em Andamento PPGAC/USP. Editor responsável: Umberto Cerasoli Jr. Designação numérica: v.3.1, pp. 81-95, 2015.

GOLDMAN, Ellen. As Others see Us: Body Movement and the Art of successful communication. Lausanne: Gordon and Breach Science Publishers S.A.,1994.

HACKNEY, Peggy. Making connections: Total Body Integration through Bartenieff's Fundamentals. Amsterdam: Gordon and Breach Publishers, 1998.

KAPLAN, E. Ann. O silêncio como resistência feminina. In: KAPLAN, E. Ann. A mulher e o cinema: os dois lados da câmera. Tradução de Helen Maria Potter Pessoa. Rio de Janeiro: Rocco, 1995. 
KESTENBERG, Judith S. The role of movement patterns in development. Vol. I, New York: Dance Notation Bureau,1977.

KESTENBERG, Judith S. Sexuality, Body Movement, and the Rhythms of Development. Northvale, N.J.: J. Aronson, 1995.

KRISTEVA, Julia. A doença da Dor: DURAS. In: KRISTEVA, Julia. Sol Negro: depressão e melancolia. Tradução de Carlota Gomes. Rio de Janeiro: Rocco, 1989.

LABAN, Rudolf. Effort: Economy in body movement. London: Northcote, s/d.

LABAN, Rudolf. A Vision of Dynamic Space. London and Philadelphia: The Falmer Press, 1984.

LABAN, Rudolf. Choreutics. Annotated and edited by Lisa Ullman. Hampshire, UK: Dance Books, 2011a.

LAUNAY, Isabelle. A la recherche d'une danse modern: Rudolf Laban et Mary Wigman. Université de Paris 8, Saint-Denis - Département Danse, 1997.

LINS, Daniel; PELBART, Peter P. (Orgs.). Nietzsche e Deleuze - Bárbaros Civilizados. São Paulo: Annablume, 2004.

MALETIC, Vera. Body, space, expression: the development of Rudolf Laban's movement and dance concepts. Berlin; New York; Amsterdam, Moutande Gruyter, 1987.

MARIGUELA, Márcio. Banda de Moebius. Psicanálise e Filosofia, 2010. Disponível em: https://marciomariguela.com.br/banda-de-mobius/. Acesso em: 03 ago. 2020.
MARTINS, Marina. A princesa dos mil e um semblantes: em busca de significação e o lugar do silêncio de Marguerite Duras, cap. 4.1 e 4.2; In: Suíte Retratos de Salomé (2005). Tese de doutorado. Orientação: Beatriz Resende. PPGT/Centro de Letras e Artes/ Universidade Federal do Estado do Rio de Janeiro, 2005.

MARTINS, Marina. Corpo Prismático: estudos do movimento (2011). Apostila do Projeto de Pesquisa Corpo Prismático: Sistema Laban/Bartenieff (c) LAPECC/UFRJ, 2011.

MIRANDA, Regina. Corpo-espaço: aspectos de uma geofilosofia do movimento. Rio de Janeiro: 7Letras, 2008.

MONTEIRO, Marli Piva. A topologia de Lacan. Revista Estudos Psicanalíticos, 2014, n.41, pp. 133-139. ISSN 0100-3437. http://pepsic.bvsalud.org/pdf/ep/ n41/n41a13.pdf. Acesso em: 02 jul. 2020.

MOORE, Carol-Lynne. Pattern and the Manipulation of Form: Laban's Choreutic Theory as a Design Source for Dance. In: Laban \& Performing Arts. Bratislávia: Bratislava in Movement Association, 2006, pp. 135-138.

OLIVEIRA, Edmar. A Deambulação. In: OLIVEIRA, Edmar. Ouvindo Vozes: Histórias do hospício e lendas do Encantado (inclui Anotações para o cemitério dos vivos, de Lima Barreto). Rio de Janeiro: Vieira \& Lent, 2009.

STAIGER, Emil. Conceitos Fundamentais da Poética. Rio de Janeiro: Tempo Brasileiro, 1997.

TARKOVSKI, Andrei. Esculpir o Tempo. Tradução de Jefferson Luiz Camargo. São Paulo: Martins Fontes, 2010. 
TURTELLI, L. S.; TAVARES, M.C.G.C.F. Movimento Humano em uma Perspectiva Psicossomática: Estudos de Judith Kestenberg. Psicologia: Teoria e Pesquisa, Brasília, 2008, Vol. 24 n. 2, pp. 217-224. Disponível em: https://www.scielo.br/pdf/ptp/v24n2/11. pdf. Acesso em: 02 mai. 2020.

VERTOV, Dziga. Disponível em: https://pt.wikipedia. org/wiki/Dziga_Vertov. Acesso em: 03 ago. 2020.

\section{- Obras de Marguerite Duras que estão no filme:}

DURAS, Marguerite. India Song. Paris: Gallimard, 1973.

DURAS, Marguerite. O Vice-consul. Tradução de Fernando Py. Rio de Janeiro: Francisco Alves, 1982.

DURAS, Marguerite. O Deslumbramento. Tradução de Ana Maria Falcão. Rio de Janeiro: Nova Fronteira, 1986a.

DURAS, Marguerite. Le Navirre Night, Césarée Césaréa, Les mains négatives, Aurelia Steiner de Melbourne, Aurelia Steiner de Vancouver, Aurelia Steiner. Filmes curta-metragem. France: Mercure de France, 1986b.

DURAS, Marguerite. A Dor. Tradução de Vera Adami. Rio de Janeiro: Nova Fronteira,1986c.

DURAS, Marguerite. Yann Andrea Steiner. Tradução de Maria Ignez Duque Estrada. Rio de Janeiro: Nova Fronteira, 1993.

DURAS, Marguerite. O Homem sentado no corredor; A doença da Morte. Tradução de Vadim Nikitin. São Paulo: Cosac Naify, 2007.

\section{Referências consultadas:}

AMIGHI, J. K.; LOMAN, S.; LEWIS, P.; SOSSIN, K. M. The meaning of movement: Developmental and clinical perspectives of the Kestenberg Movement Profile. New York: Routledge Publishers, 1999.

BARTENIEFF, Irmgard. Body Movement: Coping with the Environment. New York, Gordon and Breach, 1990.

KESTENBERG, J. Tension Flow Rhythms in The Meaning of Movement. New York: Routledge, 1999.

LABAN, Rudolf. The Language of Movement: A Guidebook to Choreutics. Boston, Plays, Inc. 1974.

LABAN, Rudolf. The Mastery of Movement. $4^{\circ} \mathrm{ed}$. Revised by Lisa Ullman. Hampshire, UK: Dance Books, 2011b.

LACAN, Jacques. Homenagem a Marguerite Duras pelo Arrebatamento de Lol. V. Stein (1965). In: Outros escritos. RJ: Jorge Zahar, 2003.

MARTINS, Marina. O Corpo Prismático revira-se entre luz e silêncio (2008). Monografia apresentada para obtenção de Certificado de Analista de Movimento (CMA) no Laban/Bartenieff Institute of Movement Studies (LIMS), orientação Karen Stud. New York, 2008.

MARTINS, Marina. Enquanto caem as folhas... (54'). Rio de Janeiro: LAPECC/UFRJ/FAPERJ, 2015. Facebook: @enquantocaemasfolhas. Disponível em: https://www.youtube.com/watch?v=MInpS2754xo. Acesso em: 02 jul. 2020. 
Este é um artigo de acesso aberto distribuido sob os termos de uma Licença Crea- tive Commons Atribuição 4.0 Internacional. Disponível em: $<$ http://creative commons.org/licenses/by/4.0>.

This is an open-access article distributed under the terms of the Creative Commons Attribution License 4.0 International. Available at: <http://creative commons.org/licenses/by/4.0>.

Ce texte en libre accès est placé sous licence Creative Commons Attribution 4.0 International. Disponible sur: <http://creativecommons.org/licenses/by/4.0>. 